\title{
Article
}

\section{Biomass Valorization of Walnut Shell for Liquefaction Efficiency}

\author{
Nives Jovičić ${ }^{1}\left(\mathbb{D}\right.$, Alan Antonović ${ }^{2, *}$, Ana Matin ${ }^{3}$, Suzana Antolović ${ }^{4}$, Sanja Kalambura ${ }^{1}$ and Tajana Krička ${ }^{3}$ (D) \\ 1 University of Applied Sciences Velika Gorica, 10410 Velika Gorica, Croatia; nives.jovicic@vvg.hr (N.J.); \\ sanja.kalambura@vvg.hr (S.K.) \\ 2 Department of Wood Technology, Faculty of Forestry and Wood Technology, University of Zagreb, \\ 10000 Zagreb, Croatia \\ 3 Department of Agricultural Technology, Faculty of Agriculture, University of Zagreb, Storage and Transport, \\ 10000 Zagreb, Croatia; amatin@agr.hr (A.M.); tkricka@agr.hr (T.K.) \\ 4 Croatian Conservation Institute, Fakultetska 4, 31000 Osijek, Croatia; suzana_antolovic@yahoo.com \\ * Correspondence: alan.antonovic@gmail.com
}

check for updates

Citation: Jovičić, N.; Antonović, A.; Matin, A.; Antolović, S.; Kalambura,

S.; Krička, T. Biomass Valorization of Walnut Shell for Liquefaction

Efficiency. Energies 2022, 15, 495.

https://doi.org/10.3390/en15020495

Academic Editors: Dino Musmarra

and Francesco Frusteri

Received: 3 December 2021

Accepted: 4 January 2022

Published: 11 January 2022

Publisher's Note: MDPI stays neutral with regard to jurisdictional claims in published maps and institutional affiliations.

Copyright: (c) 2022 by the authors. Licensee MDPI, Basel, Switzerland. This article is an open access article distributed under the terms and conditions of the Creative Commons Attribution (CC BY) license (https:// creativecommons.org/licenses/by/ $4.0 /)$.

\begin{abstract}
Globally, lignocellulosic biomass has great potential for industrial production of materials and products, but this resource must be used in an environmentally friendly, socially acceptable and sustainable manner. Wood and agricultural residues such as walnut shells as lignocellulosic biomass are one of the most affordable and important renewable resources in the world, which can partially replace fossil resources. The overall objective of the research is to provide background information that supports new applications of walnut shells in a biorefinery context and to increase the economic value of these non-wood forest products. This paper presents the properties characterization of liquefied biomass according to their chemical composition. All results were compared to liquefied wood. In this study, the liquefaction properties of five different walnut shell particle sizes were determined using glycerol as the liquefaction reagent under defined reaction conditions. The liquefied biomass was characterized for properties such as percentage residue, degree of liquefaction, and hydroxyl $\mathrm{OH}$ numbers. The chemical composition of the same biomass was investigated for its influence on the liquefaction properties. Accordingly, the main objective of this study was to determine the liquefaction properties of different particle sizes as a function of their chemical composition, also in comparison with the chemical composition of wood. The study revealed that walnut shell biomass can be effectively liquefied into glycerol using $\mathrm{H}_{2} \mathrm{SO}_{4}$ as the catalyst, with liquefaction efficiency ranging from 89.21 to $90.98 \%$.
\end{abstract}

Keywords: biomass liquefaction; biorefinery; hydroxyl number; lignocellulose biomass; liquefaction degree; residue percentage; walnut shell; wood liquefaction

\section{Introduction}

Agriculture is very important for the overall development of individual countries and regions, but at the same time it can have a negative impact on the state of the environment. Agricultural production also produces waste and agricultural waste is available in large quantities in both the EU and the Republic of Croatia and therefore has the potential to become a source of renewable raw materials. Agricultural biomass is an important source of renewable raw materials [1] with great production potential, and the use of biomass as a raw material is continuously increasing throughout Europe [2,3]. A large part of agricultural waste consists of lignocellulosic material, and the main properties of lignocellulosic biomass are very good strength, flammability, biodegradability and reactivity [4]. Agricultural biomass can be used as a raw material for the production of natural fibers and is particularly interesting from the point of view of environmental protection, since it is available, renewable and acceptable as a raw material source independent of petroleum products [5-7].

In the 20th and 21st centuries, there has been intense technological and social progress in all spheres of human life. Industrialization and globalization, as well as the consumer 
mentality of society and the linear economy, have led to increasing production and exponential consumption of material goods, thus drawing resources from nature [8]. The scarcity of natural resources and the negative environmental impact caused by consumption require the discovery of new models for their sustainable use $[9,10]$. As natural resources are dwindling and other amounts of waste are growing, the conversion of agricultural waste into a new resource represents an opportunity for the development of a circular economy. The European Union is committed to the development of a circular economy, so the European Strategy for Smart, Sustainable and Inclusive Growth as one of the basic three development priorities proposes sustainable growth or promoting a resource-efficient, greener and more competitive economy [7]. The circular economy does not reject raw materials that can still be used to produce new products. In this way, limited resources are less depleted, and waste is reduced, thus opening a new front of green technologies and creating a new atmosphere of a green economy [11].

Given the global economic and environmental issues associated with the large use of petrochemical products, there has been a growing interest in researching the possibilities of using waste biomass over the past decade $[12,13]$.

Research is developing in two directions, one is the development of new chemicals, resins and adhesives and the other is the development of substitutes for fossil fuels [14]. In line with the principles of sustainable development, methods and technologies for the alternative and, above all, effective use of biomass to obtain "green" products and the use of natural polymeric materials as alternatives to petrochemical products are being investigated $[15,16]$.

With the growing trends of production based on the biological basis of products, the concept of biorefinery is continuously gaining in importance [17]. Although the definition of the term biorefinery itself is subject to debate, the ultimate goal of biorefinery production is to create diverse products from different biomass as raw materials $[16,18]$. Processes and technologies from different fields, including polymer chemistry, bioengineering and agriculture [19-21], used in biorefineries can result in different products such as fuel, energy, chemicals and different matter [22-24].

After walnut kernels are used for food purposes, the shell remains as a by-product or waste, although walnut shell biomass is also a renewable source of raw material [25]. World production of walnuts is over 3.7 million $t$. China is the largest producer, with 1.06 million $t$ and the other major producers are Iran, the USA, and Turkey (FAOSTAT) while walnut production in Portugal was $4000 \mathrm{t}$. The walnut kernels are used as food and they have rich nutrient composition: very rich in polyunsaturated fatty acids $(52-70 \%)$, proteins (12-24\%, particularly rich in essential amino acids), and minerals $(1.5-2 \%)$ and have a wide variety of flavonoids, polyphenols, and phenolic acids [26].

The structural polymers of lignocellulosic materials are cellulose, hemicellulose, and lignin, and their proportions depend on the plant species [27]. In general, lignocellulose contains $25-50 \%$ cellulose, $20-40 \%$ hemicellulose, and $10-35 \%$ lignin $[28,29]$.

Development of new technologies for the effective utilization of biomass will enable the production of environmentally friendly bio-based products such as biofuels, bioenergy, biochemicals and biomaterials [30]. Common methods used in the production of bio-based products from biomass are biochemical and thermochemical conversion methods [31]. Of the thermochemical conversion methods, the most attention was drawn to the wood liquefaction in the presence of some organic reagents [32,33].

The influence of biomass chemical composition on liquefaction behavior and the chemical properties of liquefied biomass have not been studied much. Liquefaction reactions with phenols and polyhydric alcohols are the most interesting methods in the previous studies and literature. After the discovery of the wood liquefaction phenomena, research of different liquefaction parameters was conducted in terms of increasing of biomass concentration in liquefaction mixture, achieving the real liquefaction degree with respect to solubility properties of liquefied biomass in organic solvents, comprehension and understanding of the wood liquefaction mechanism, and further application [33,34]. 
Although there have been many studies on wood biomass liquefication, there are gaps in the literature on agricultural lignocellulose biomass liquefication, which led to the main objective of this study: to determine the liquefaction properties of walnut shell, as well as compare them to the chemical composition of wood. In this research the percentage residues, liquefaction degree and hydroxyl $\mathrm{OH}$-numbers were determined as liquefaction properties of walnut shell biomass.

\section{Materials and Methods}

For this research we used biomass of walnut shell from the domestic cultivar Šejnovo (Sisak-Moslavina County, Dvor municipality, geographical coordinates of the experimental orchard: $4504^{\prime} 23.5^{\prime \prime} \mathrm{N} 16^{\circ} 22^{\prime} 35.0^{\prime \prime} \mathrm{E}$ ). Walnuts were collected by random selection of only healthy fruits from eight different trees in the orchard. An amount of $20 \mathrm{~kg}$ was collected from each tree. From the total amount $(160 \mathrm{~kg})$ of walnuts, a final sample $(40 \mathrm{~kg})$ was prepared by the method of quartering for further chemical analyzes. After separation of the shell and the kernel of the walnut, the shell air-dried naturally.

All results were compared with liquefied wood, with the four most common types of hardwood species namely black poplar (Populus nigra L.), beech (Fagus sylvatica), sessile oak (Quercus petraea Liebl.) and common oak (Quercus robur L.) and two softwood species namely common fir (Abies alba Mill.) and spruce (Picea abies Karst.) [34].

Air-dried samples were milled using a knife-mill Fritsch-Pulverisette 19 on different particles size. After milling, samples were sieved through standardized sieves. After sieving, five ranges of particle size were selected for the experiments: smaller than $0.3 \mathrm{~mm}$; $0.3-0.63 \mathrm{~mm} ; 0.63-1.25 \mathrm{~mm} ; 1.25-1.4 \mathrm{~mm} ; 1.4-1.6 \mathrm{~mm}$.

For screening, laboratory electromagnetic sieves shaker Cisa RP-08 (shaking time $t=15 \pm 1 \mathrm{~min}$ ) was used (TAPPI T $264 \mathrm{~cm}-97)$. After sample grinding and sieving, three smaller samples were taken on which all the chemical analysis and liquefaction were performed, and the results are presented as the mean values of these three samples.

The data were analyzed by means of the statistical software package SAS v 9.3 (Cary, NC, USA). The graphs are generated based upon the results of experiments using SageMath version 9.2 NoteBook package. The functions used are list_plot3D and list_plot2D.

\subsection{Chemical Composition Analysis}

In our research, non-combustible and combustible properties, heating value, lignocellulose composition and macro-element content were investigated. The chemical characterization of walnut shell was made on one granulometric fraction- $-0.63-1.25 \mathrm{~mm}$. The analyses of walnut shell included determination of the moisture, ash, coke, fixed carbon and volatile matter content, C, H, N, S the content and the higher (HHV) and lower (LHV) heating values.

Moisture content was determined according to protocol (HRN EN 18134-2:2015) in a laboratory dryer (INKO ST-40, Zagreb, Croatia). Ash content (HRN EN ISO 18122:2015) and coke content (CEN/TS 15148:2009) were analyzed in a muffle furnace (Nabertherm B170, Lilienthal, Germany). Fixed carbon and volatile matter content were determined according to protocol (EN 15148:2009) by calculation. The content of nitrogen (N) was determined according to protocol (HRN EN ISO 16948:2015), carbon (C) and hydrogen (H) (HRN EN ISO 16948:2015) and sulfur (S) (HRN EN ISO 16994:2015) in CHNS analyzer (Elementar Analyzensysteme $\mathrm{GmbH}$, Langenselbold, Germany), while oxygen (O) was calculated as the rest of the $\mathrm{C}, \mathrm{H}, \mathrm{N}$, S elements. The heating values, HHV and LHV, were determined according to protocol (HRN EN 14918:2010) using an IKA C200 oxygen bomb calorimeter (IKA Analysentechnik GmbH, Heitersheim, Germany).

Isolation methods for determining the chemical composition (wet chemistry), namely ash, accessory materials (extractives), cellulose, hemicellulose (polyoses) and lignin were conducted in compliance with previous studies [32-37]. Sample chemical compositional analysis consisted of a series of isolation methods of the main components, which can be schematically presented as shown in Figure 1. 


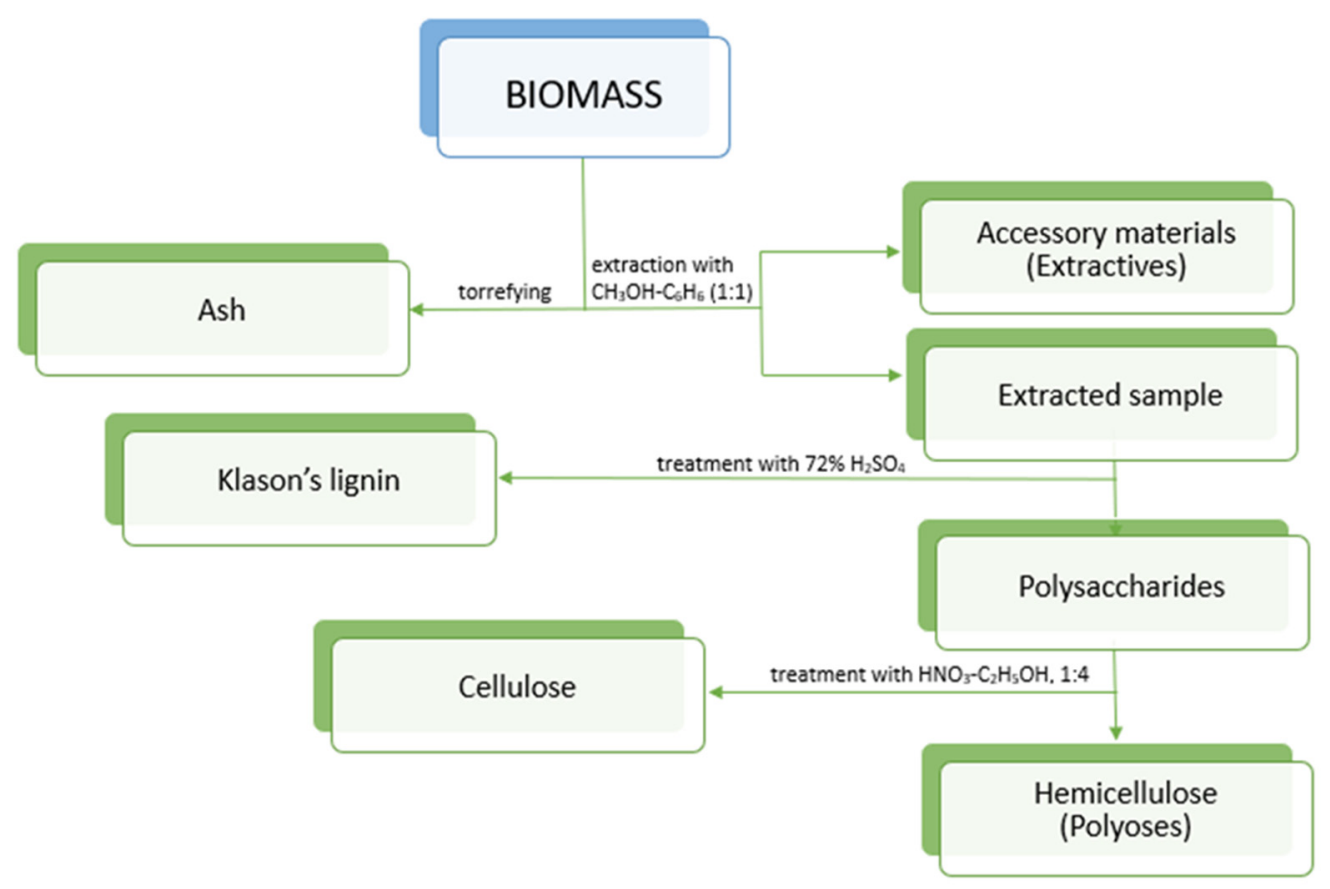

Figure 1. Schematic view of sample chemical analysis [34].

Isolation methods for determining the content of chemical composition (wet chemistry), namely ash, accessory materials (extractives), cellulose, hemicellulose (polyoses) and lignin were conducted in compliance with previous studies [33,34]. A small portion of the prepared sample was first used to determine the ash content, and the other major part for prior sample extraction (treatment with a solvent mixture of methanol, $\mathrm{CH}_{3} \mathrm{OH}$ and benzene, $\mathrm{C}_{6} \mathrm{H}_{6}$ in the volume ratio 1:1) to remove the accessory materials from the sample which could interfere during further chemical analysis. Thus, additional residual solid content was determined as a content of accessory materials or extractives [34]. Furthermore, sulfonic acid lignin or Klason's lignin (treatment with $72 \%$ sulfuric acid, $\mathrm{H}_{2} \mathrm{SO}_{4}$ ) and the polysaccharides cellulose (by treatment with a solvent mixture of nitric acid, $\mathrm{HNO}_{3}$ and ethanol, $\mathrm{C}_{2} \mathrm{H}_{5} \mathrm{OH}$ in a volume ratio of 1:4) was isolated from the extracted sample. The content of hemicellulose (polyose) was determined by calculation according to share of other mentioned components in the samples. The hemicellulose content was calculated according to next expression: $\mathrm{WP}=100-(\% \mathrm{~A}+\% \mathrm{AM}+\% \mathrm{C}+\% \mathrm{~L})$ in \% [34]. All used chemicals were high purity (p.a.) and were obtained from commercial sources.

\subsection{Liquefied Biomass Preparation}

Liquefied biomass was prepared based on a previous study according to Antonović et al., 2019 (Figure 2).

Smaller obtained samples (without any prior chemical treatment) of different particle size were liquefied with mixture of glycerol and sulfuric acid $\left(\mathrm{H}_{2} \mathrm{SO}_{4}\right)$ by acid catalyst (biomass/glycerol $=1: 5$, sulfuric acid as catalyst $(3 \mathrm{wt} \%)$ ) method for $120 \mathrm{~min}$ at $150{ }^{\circ} \mathrm{C}$. Undissolved residue (UR) percentage and wood liquefaction degree (LD), as well as hydroxyl number (OH-number) were determined as values that describe polymer properties of liquefied biomass for the purpose of selecting optimal liquefaction parameters. 


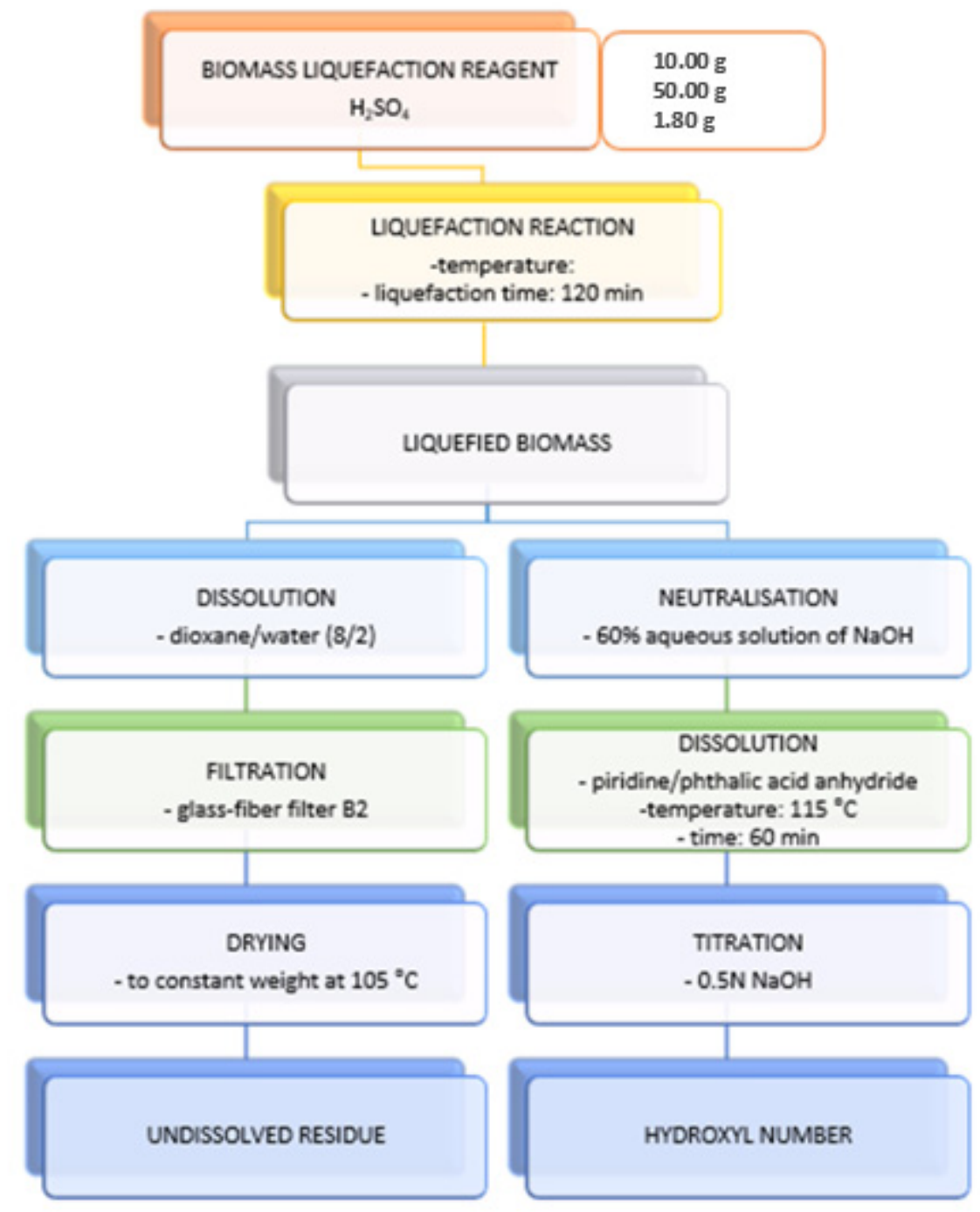

Figure 2. Liquefaction procedure and analytical methods for liquefied biomass characterization [34].

\subsection{Undissolved Residue and Liquefaction Degree}

After the liquefaction reaction, undissolved residue of liquefied biomass was determined by the dioxane/water mixture, which is recommended as a universal diluent for liquefied biomasses. An amount of $1 \mathrm{~g}$ of liquefied biomass was diluted with dioxane/water mixture in a ratio 8/2, and then stirred in a magnetic stirrer for $60 \mathrm{~min}$. After that mixture was filtrated through a glass-fiber filter B2 in a vacuum. The residue was rinsed by the same diluent repeatedly until a colorless filtrate was obtained, and then the undissolved residue was dried in oven at $105 \pm 2{ }^{\circ} \mathrm{C}$ to a constant weight. Undissolved residue percentage was calculated by the following equation (according to Antonović et al. [34]):

$$
\mathrm{UR}=\frac{\text { weight of undissolved residue }(\mathrm{g})}{\text { weight of liquefied } \operatorname{wood}(\mathrm{g})} \times 100(\%)
$$

Liquefaction degree (LD) percentage was calculated according to the next equation:

$$
\mathrm{LD}=100-\mathrm{UR} \quad(\%)
$$

\subsection{Hydroxyl Number (OH-Number)}

An amount of 1.5-2.5 g of liquefied biomass was weighed into two $250 \mathrm{~mL}$ volume Erlenmeyer's flasks and then $10 \mathrm{~mL}$ of reagent was added. The reagent was a mixture of pyridine and phthalic acid anhydride. In the third flask we added only reagent, for 
determination of a blank solution. Each flask was equipped with a condenser and magnetic stirrer with heater, and each magnetic stirrer had an oil bath, which was used for keeping a constant temperature at $115^{\circ} \mathrm{C}$, and with the help of a condenser we condensated the reagent. The mixture in the flask was heated for exactly one hour measured from the moment when the first drop condensed. After, $50 \mathrm{~mL}$ of pyridine was added to the cooled mixture and titrated with the $0.5 \mathrm{M}$ sodium hydroxide solution with the presence of phenolphthalein until an equivalent point was reached (the bright red staining should not appear for at least $30 \mathrm{~s}$ ). The hydroxyl number for liquefied biomass sample in $\mathrm{mg} \mathrm{KOH} / \mathrm{g}$ was calculated from the following equation (according to Antonović et al. [34]):

$$
\mathrm{OH}-\text { number }=\frac{(\mathrm{B}-\mathrm{A}) \times \mathrm{c}_{\mathrm{NaOH}} \times 56.1}{\mathrm{~m}} \quad(\mathrm{mg} \mathrm{KOH} / \mathrm{g})
$$

where: A-volume of the $\mathrm{NaOH}$ solution used for sample titration (ml); B-volume of the $\mathrm{NaOH}$ solution used for blank solution titration; $\mathrm{C}_{\mathrm{NaOH}}-$ normality of the $\mathrm{NaOH}$ solution (M); m-weight of liquefied biomass sample.

The dry matter content of different particle sizes was determined by drying a sample in an oven, at two temperatures $\left(102{ }^{\circ} \mathrm{C}\right.$ and $\left.150^{\circ} \mathrm{C}\right)$, until a constant weight was obtained.

\section{Results}

\subsection{Chemical Composition of Walnut Shell}

The analysis of non-combustible properties determined: nitrogen $(\mathrm{N})$, water $\left(\mathrm{H}_{2} \mathrm{O}\right)$, ash, coke, fixed carbon $\left(\mathrm{C}_{\mathrm{fix}}\right)$, and the obtained values are shown in Table 1.

Table 1. Non-combustible matter content in the walnut shell.

\begin{tabular}{lccccc}
\hline \multirow{3}{*}{ Walnut shell } & Moisture & Ash & Coke & $\begin{array}{c}\text { Fixed } \\
\text { Carbon }\end{array}$ & Nitrogen \\
\cline { 2 - 6 } & \multicolumn{5}{c}{$(\%$, mass $)$} \\
\cline { 2 - 6 } & $12.23 \pm 0.10$ & $1.26 \pm 0.08$ & $17.15 \pm 0.30$ & $15.89 \pm 0.47$ & $0.56 \pm 0.14$ \\
\hline
\end{tabular}

Carbon $(\mathrm{C})$, hydrogen $(\mathrm{H})$, sulfur $(\mathrm{S})$, oxygen $(\mathrm{O})$, volatile matter contents, the higher heating value (HHV) and the lower heating value (LHV) are considered as combustible properties. The obtained values are shown in Table 2.

Table 2. Combustible matter content in the walnut shell.

\begin{tabular}{|c|c|c|c|c|c|c|c|}
\hline \multirow{3}{*}{ Walnut shell } & Carbon & Sulphur & Oxygen & Hydrogen & $\begin{array}{l}\text { Volatile } \\
\text { Matter }\end{array}$ & HHV & LHV \\
\hline & \multicolumn{7}{|c|}{$(\%$, mass $)\left(\mathrm{MJ} \mathrm{kg}^{-1}\right)$} \\
\hline & $52.11 \pm 2.26$ & $0.23 \pm 0.06$ & $42.20 \pm 1.08$ & $5.86 \pm 0.07$ & $70.62 \pm 0.58$ & $17.93 \pm 0.51$ & $16.66 \pm 0.47$ \\
\hline
\end{tabular}

Biomass chemical composition namely accessory materials (extractives) content, ash content, cellulose content, polyoses (hemicellulose) content and lignin content of the different species are given in Table 3.

Table 3. Chemical composition of walnut shell.

\begin{tabular}{ccccccc}
\hline Biomass & \% A & \% AM & \% H & \% C & \% P & \% L \\
\hline Walnut shell & $1.23 \pm 0.07$ & $2.46 \pm 0.08$ & $42.45 \pm 0.78$ & $32.62 \pm 0.22$ & $9.82 \pm 0.80$ & $53.87 \pm 0.85$ \\
\hline \multicolumn{7}{c}{ A-ash; AM-accessory material; H-holocellulose; C-cellulose; P-polyoses; L-lignin. }
\end{tabular}




\subsection{Liquefaction Properties of Liquefied Biomass}

The liquefaction properties of liquefied different particle biomass size namely undissolved residue, liquefaction degree and hydroxyl number are given in Table 4.

Table 4. Liquefaction properties of different walnut shell particle size.

\begin{tabular}{|c|c|c|c|}
\hline Particle size & $\%$ UR & $\%$ LD & $\begin{array}{c}\mathrm{OH} \\
\text { (mg KOH/g) }\end{array}$ \\
\hline Walnut shell PS $<0.3$ & $9.16 \pm 1.08^{a}$ & $90.84 \pm 1.08^{\mathrm{a}}$ & $364.00 \pm 3.12^{a}$ \\
\hline Walnut shell PS 0.3-0.6 & $902 \pm 0.76^{\mathrm{a}}$ & $90.98 \pm 0.76^{a}$ & $359.33 \pm 4.04^{\mathrm{a}}$ \\
\hline Walnut shell PS 0.6-1.25 & $9.42 \pm 2.68^{a}$ & $90.58 \pm 2.68^{a}$ & $385.67 \pm 5.69^{b}$ \\
\hline Walnut shell PS 1.25-1.4 & $10.79 \pm 1.23^{a}$ & $89.21 \pm 1.23^{a}$ & $426.50 \pm 5.68^{c}$ \\
\hline \multirow[t]{2}{*}{ Walnut shell PS > 1.4} & $10.21 \pm 0.18^{a}$ & $89.79 \pm 0.18^{a}$ & $450.00 \pm 3.91^{d}$ \\
\hline & $\begin{array}{cc}\mathrm{F} & \mathrm{P} \\
0.817 & 0.543\end{array}$ & $\begin{array}{cc}\mathrm{F} & \mathrm{P} \\
0.817 & 0.543\end{array}$ & $\begin{array}{cc}\text { F } & \text { P } \\
220.8 & <0.005\end{array}$ \\
\hline
\end{tabular}

UR—undissolved residue; LD—liquefaction degree; $\mathrm{OH}$-hydroxyl number (different small letters (a, b, c, d) are significantly different $(p<0.05))$.

Among the liquefied different biomass particle sizes of walnut shell, the lowest undissolved residue content was achieved with granulation $0.3-0.6 \mathrm{~mm}$, so the highest liquefaction degree was achieved with the same particle size (Figure 3).

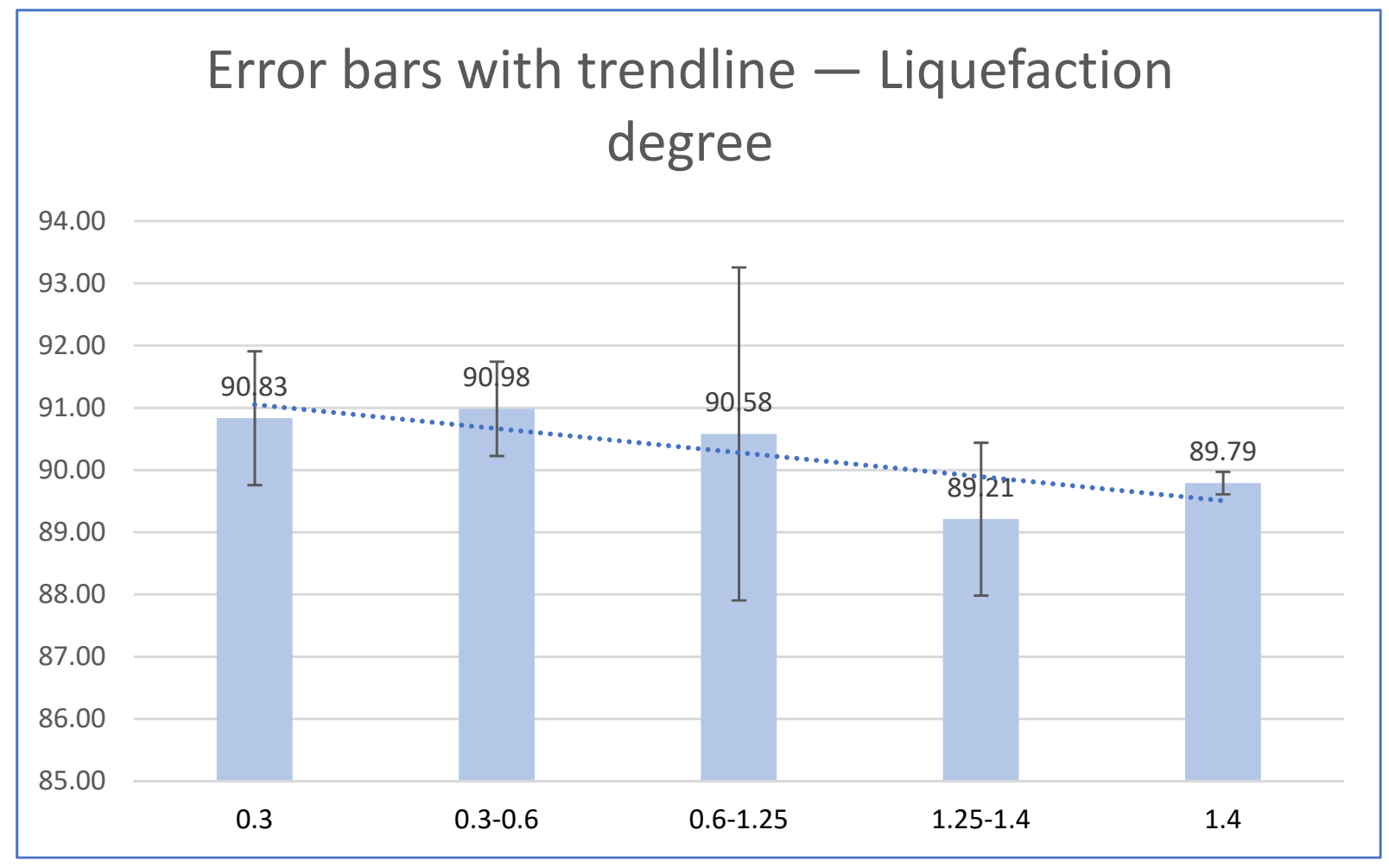

Figure 3. Liquefaction degree as a function of particle size.

Obtained results have shown that liquefaction degree depends on particle size and with a decrease in granulation there is an increase in liquefaction degree. Among the liquefied different biomass particle sizes, the lowest $\mathrm{OH}$-number was achieved with granulation 0.3-0.6 mm (Figure 4). 


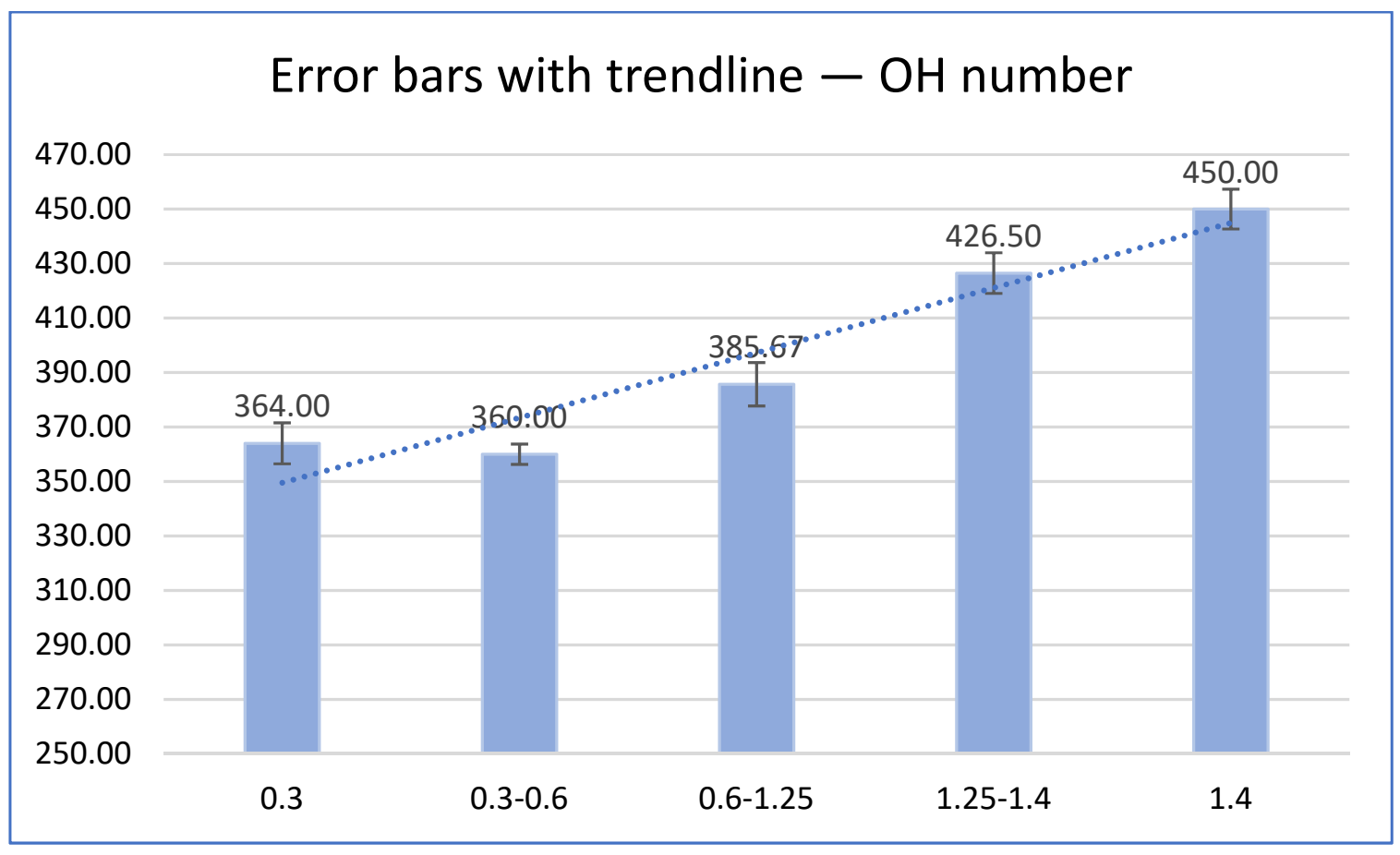

Figure 4. OH-number as a function of particle size.

Obtained results have shown that dry matter depends on temperature and particle size. The lowest content of dry matter was at the smallest and at the biggest particle size of walnut shell (Table 5 and Figure 5).

Table 5. Relationship between dry matter (\%) and particle size (the same small letter (a) indicates that there is no significantly difference at $p<0.05$ ).

\begin{tabular}{|c|c|c|c|c|}
\hline \multirow{2}{*}{ Particle Size } & \multicolumn{4}{|c|}{ Dry Matter (\%) } \\
\hline & \multicolumn{2}{|c|}{$102{ }^{\circ} \mathrm{C}$} & \multicolumn{2}{|c|}{$150^{\circ} \mathrm{C}$} \\
\hline Walnut shell PS $<0.3$ & \multicolumn{2}{|c|}{$68.71 \pm 0.79^{a}$} & \multicolumn{2}{|c|}{$53.82 \pm 0.85^{a}$} \\
\hline Walnut shell PS 0.30-0.60 & \multicolumn{2}{|c|}{$68.10 \pm 4.13^{\mathrm{a}}$} & \multicolumn{2}{|c|}{$53.82 \pm 1.19^{a}$} \\
\hline Walnut shell PS 0.60-1.25 & \multicolumn{2}{|c|}{$69.89 \pm 6.81^{a}$} & \multicolumn{2}{|c|}{$56.10 \pm 1.79^{a}$} \\
\hline Walnut shell PS 1.25-1.40 & \multicolumn{2}{|c|}{$68.24 \pm 3.03^{a}$} & \multicolumn{2}{|c|}{$53.85 \pm 2.16^{a}$} \\
\hline \multirow[t]{3}{*}{ Walnut shell PS > 1.40} & \multicolumn{2}{|c|}{$66.66 \pm 5.12^{a}$} & \multicolumn{2}{|c|}{$52.54 \pm 1.17^{\mathrm{a}}$} \\
\hline & $\mathrm{F}$ & $\mathrm{P}$ & $\mathrm{F}$ & $\mathrm{P}$ \\
\hline & 0.205 & 0.93 & 2.193 & 0.143 \\
\hline
\end{tabular}

Results have also shown that the relationship between dry matter and particle size remains the same regardless of temperature, i.e., given the particle size interval, the change of dry matter is the same no matter the temperature (Figure 5). 


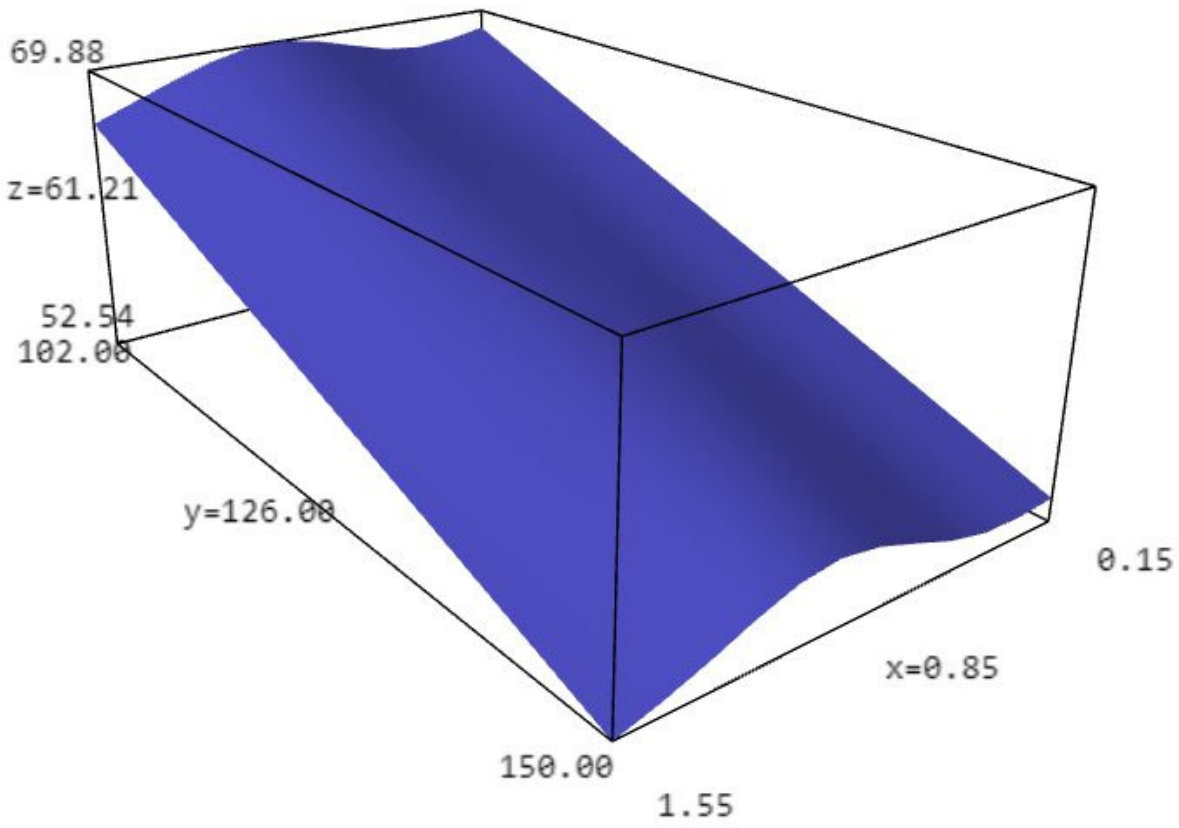

Figure 5. Dry matter dependence on temperature and particle size ( $x$ - particle size; $y$-temperature; z-dry matter).

\section{Discussion}

Moisture content depends on environmental air temperature during the winter season, and it is one of the most important parameters when it comes to fuel properties. The moisture content was $12.23 \%$. Ash content, which is also one of the main factors of biomass quality, since higher amounts of ash diminishes the quality of fuels, especially solid ones, was $1.26 \%$. Ash originates simultaneously from natural and technogenic inorganic, organic and fluid matter during biomass combustion [35]. This result is in the range reported for nut shells, although a large variation of values may be found for a specific nut shell. Queirós [36] also reported a low content of ash for walnut shell $(0.7 \%)$. Coke content and fixed carbon content are considered positive properties of biomass because they represent the quantity of energy released by the combustion of a specific amount of biomass [38]. In our study, the obtained fixed carbon content in walnut shell was $15.89 \%$ and coke content was $17.15 \%$. From an environmental point of view, nitrogen contributes to the increase in greenhouse gases, and is considered to be an unfavorable element in biomass. Content of nitrogen in walnut shell was $0.56 \%$. The obtained results are slightly lower than those obtained by Demirbas [39] who determined the values of non-combustible substances in walnut shell as $2.80 \%$ ash, $37.90 \%$ fixed carbon and $1.50 \%$ nitrogen $(\mathrm{N})$.

In the chemical composition of fuel, carbon (C) is one of the basic elements and makes up to $95 \%$. The amount of carbon also determines the quality of fuel; i.e. by increasing the carbon content the quality of fuel improves. The carbon content in the walnut shell was $52.11 \%$ while the hydrogen content was $5.86 \%$. The obtained results are slightly higher than those obtained by Matin et al., [40] who found the carbon content in walnut shell to be from 57.55 to $58.01 \%$, depending on the variety, while Demirbaş [39] found that walnut shell contains $53.50 \%$ carbon (C). Hydrogen is the second most important ingredient in fuel, which with its high energy increases the thermal value of the fuel, and by burning it creates a visible flame.

By its share in fuel, oxygen reduces the calorific value of fuel. Oxygen content was $42.20 \%$.

Sulfur (S) is the least represented element and it is usually found in traces in biomass. The obtained values $(0.23 \%)$ are slightly higher than stated by Demirbaş [39] who found 
that walnut shell contains $0.10 \%$ sulfur (S) while Matin et al. [40] found even lower values $(0.04-0.05 \%)$.

Accessory materials content was $2.46 \%$, cellulose content $32.60 \%$, polyoses content $9.82 \%$. Lignin content was very high, $58.22 \%$, compared to results $(29.90 \%)$ reported by Queirós et al. [36].

Obtained results have shown that walnut shell biomass has different chemical composition compared to wood chemical composition investigated by Antonović et al. [34].

The biggest difference between walnut shell biomass and wood is in the content of cellulose and lignin (cellulose content from 39.18-48.38\%, polyoses content from 22.69$32.41 \%$ and lignin content from $21.82-27.96 \%$ ).

Nut shells are in general characterized by being highly lignified: lignin content in walnut shells is between 27.4-52.3\% [39,41-45], in almond shells between $20.4-28.4 \%$ [39,42, 46], in hazelnut shells between $27.2-43.0 \%$ [39,45], and in peanut shells $35.3 \%$ [40]. In regard to cellulose content, the following values were reported for different shells, $25.6-34.5 \%$ for walnut, $22.4-50.7 \%$ for almond, $22.1 \%$ for peanut, and $26.7-40.5 \%$ for hazelnut $[39,42,47]$. Although our results on chemical composition differ from the values presented by Ning [48] and the one reported by González-García [49], the obtained results are within the limits of the values of the mentioned studies and investigations [39,41-47].

Liquefaction comprises a complex set of reactions taking place on the polymeric components of biomass. They include derivatization such as esterification or etherification of free hydroxyl groups in cellulose or lignin as well as reactions that break the polymer chain of cellulose. In addition, liquefaction is affected by physical constraints on biomass reactivity such as the high crystallinity of cellulose. The tight packing of cellulose in the crystalline domains makes the reaction kinetics of otherwise reactive functional groups dependent on the diffusion of reagents into the tightly packed system. To overcome this limitation and speed up the liquefaction, increasingly harsh catalysts and reaction conditions, mainly mineral acids and high temperatures, have been employed. In short, macromolecule compounds in biomass are degraded into micro molecules and the obtained small molecules are unstable, reactive and can re-polymerize into oily products with a wide range of molecular weight distribution $[33,34]$.

Undissolved residue content among the liquefied walnut shell varied from 9.02$10.79 \%$, liquefaction degree content from 89.21-90.98\% and hydroxyl $(\mathrm{OH})$-number from 359-450 mg KOH/g. Obtained results have shown that walnut shell biomass has a different chemical composition compared to wood chemical composition investigated by Antonović et al., [34]. The hardwood species exhibited higher undissolved residue $(11.53 \%$ for beech to $8.02 \%$ for common oak) and lower liquefaction degree content $(88.47 \%$ for beech to $91.98 \%$ for common oak) as compared to softwood species (undissolved residue was 5.06\% for spruce and $6.20 \%$ for common oak). Within hardwood species differences were also observed in the same liquefaction properties. Although softwoods show the smallest undissolved residue content and the highest liquefaction degree content compared with hardwood, the hardwoods show a much higher $\mathrm{OH}$-number. Hydroxyl number is very important in further liquefied wood application for various bioproducts, therefore should be given priority over undissolved residue and liquefaction degree [34]. According to that all hardwoods (692-798 mg KOH/g), and especially beech (798 $\mathrm{mg} \mathrm{KOH} / \mathrm{g}$ ), show better properties in further application compared to walnut shell (359 to $450 \mathrm{mg} \mathrm{KOH} / \mathrm{g}$ ). So, the biggest difference between walnut shell biomass and wood is $\mathrm{OH}$-number.

Liquefaction degree content in walnut shell varied from $89.21-90.98 \%$, which is similar to the results obtained for liquified wood (88.47-94.94\%).

Results have shown that $\mathrm{OH}$-number depends on particle size and with an increase in granulation there is an increase in $\mathrm{OH}$-number. Results also shown that the relationship between dry matter and particle size remains the same regardless of temperature, i.e., given the particle size interval, the change of dry matter is the same no matter the temperature. 


\section{Conclusions}

The study revealed that walnut shell biomass can effectively be liquefied in glycerol using $\mathrm{H}_{2} \mathrm{SO}_{4}$ as a catalyst with liquefaction efficiency ranging from $89.21-90.98 \%$ under the same liquefaction conditions, which is similar to the results obtained for liquified wood (88.47-94.94\%).

Hydroxyl number as the most important liquefaction property in further application for various bioproducts have priority over undissolved residue and liquefaction degree, and according to that bigger particle size of walnut shell biomass show better properties in further application compared to smaller. Results have shown that $\mathrm{OH}$-number depends on particle size and with the increase in granulation there is an increase in $\mathrm{OH}-$ number, so the biggest particle size $(>1.4)$ had the biggest $\mathrm{OH}$ number (450). The lowest content of dry matter was at the smallest and at the biggest particle size of walnut shell so the obtained results have shown that the relationship between dry matter and particle size remains the same regardless of temperature, i.e., given the particle size interval, the change of dry matter is the same no matter the temperature.

The use of a catalytic liquefaction method with polyhydric alcohol glycerol was found to be suitable for liquefying walnut shells. Finally, the present study revealed unimaginable opportunities for scientific research and development aimed at novel bioproducts from liquefied biomass and opened new challenges in exploring natural, ecologically sound products with unlimited raw materials.

Author Contributions: Conceptualization, N.J., A.A. and T.K.; methodology, A.A. and T.K.; software, A.M.; formal analysis, A.M.; investigation, N.J. and S.A.; writing-original draft preparation, N.J.; writing-review and editing, T.K., S.K. and A.A.; visualization, A.M. and N.J. All authors have read and agreed to the published version of the manuscript.

Funding: The research received funding from European Structural and Investment Funds and Operational Programme Competitiveness and Cohesion via KK.01.2.1.02.0236 project: "Development of an Innovative Technical-Technological Line for the Production of Advanced Bioadhesives Based on Liquefied Wood-LiqWOODTech".

Institutional Review Board Statement: Not applicable.

Informed Consent Statement: Not applicable.

Data Availability Statement: Upon a reasonable request, all data in three replicates will be provided by authors.

Conflicts of Interest: The authors declare no conflict of interest.

\section{References}

1. Kiš, D.; Jovičić, N.; Matin, A.; Kalambura, S.; Vila, S.; Guberac, S. Energy value of agricultural spelt residue (Triticum spelta L.)-forgotten cultures. Tech. Gaz. 2017, 24, 369-373. [CrossRef]

2. Bilandžija, N.; Voća, N.; Jelčić, B.; Jurišić, V.; Matin, A.; Grubor, M.; Krička, T. Evaluation of Croatian agricultural solid biomass energy potential. Renew. Sustain. Energy Rev. 2018, 93, 225-230. [CrossRef]

3. Krička, T.; Matin, A.; Bilandžija, N.; Jurišić, V.; Antonović, A.; Voća, N.; Grubor, M. Biomass valorization of Arundo donax L., Miscanthus $\times$ giganteus and Sida hermaphrodita for biofuel production. Int. Agrophysics 2017, 31, 575-581. [CrossRef]

4. Putro, J.; Soetaredjo, F.; Lin, S.-Y.; Ju, Y.-H.; Ismadji, S. Pretreatment and Conversion of Lignocellulose Biomass into Valuable Chemicals. R. Soc. Chem. 2016, 6, 46834-46852. [CrossRef]

5. Krička, T.; Jurišić, V.; Matin, A.; Bilandžija, N.; Antonović, A. Mogućnosti pretvorbe i iskorištenja ostataka poljoprivredne biomase nakon procesa pirolize. In Proceedings of the 51st Croatian and 11th International Symposium on Agriculture, Opatija, Croatia, 15-18 February 2016; pp. 485-489.

6. Bhat Subrahmanya, K.; Yashas Gowda, T.G.; Sanjay, M.R.; Yogesha, B. Polymer Matrix-Natural Fiber Composites: An Overview. Cogent Eng. 2018, 5, 1.

7. Maj, G. Emission Factors and Energy Properties of Agro and Forest Biomass in Aspect of Sustainability of Energy Sector. Energies 2018, 11, 1516. [CrossRef]

8. Ragauskas, A.J.; Williams, C.K.; Davison, B.H.; Britovsek, G.; Cairney, J.; Eckert, C.A. The path forward for biofuels and biomaterials. Science 2006, 311, 484. [CrossRef] 
9. Mosier, N.; Wyman, C.; Dale, B.; Elander, R.; Lee, Y.Y.; Holtzapple, M.; Ladisch, M. Features of promising technologies for pretreatment of lignocellulosic biomass. Bioresour. Technol. 2005, 96, 673-686. [CrossRef]

10. European Commission. Communication from the Commission to the European Parliament, the Council, the European Economic and Social Committee and the Committee of the Regions, Closing the Circle-EU Circular Economy Action Plan. 2015. Available online: https:/ / eur-lex.europa.eu/legal-content/HR/TXT/HTML/?uri=CELEX:52015DC0614\&from=EN (accessed on 1 October 2021).

11. Bismarck, A.; Baltazar-Y-Jimenez, A.; Sarikakis, K. Green composites as Panacea? Socio-economic aspects of green materials. Environ. Dev. Sustain. 2006, 8, 445-463. [CrossRef]

12. Iqbal, H.M.N.; Kyazze, G.; Keshavarz, T. Advances in valorization of lignocellulosic materials by bio-technology: An overview. BioResources 2013, 8, 3157-3176. [CrossRef]

13. Menon, V.; Rao, M. Trends in bioconversion of lignocellulose: Biofuels, platform chemicals \& biorefinery concept. Prog. Energy Combust. Sci. 2012, 38, 522-550.

14. Kurimoto, Y.; Doi, S.; Tamura, Y. Species effects on wood-liquefaction in polyhydric alcohols. Holzforschung 1999, 53, 617-622. [CrossRef]

15. Lee, S.Y. Deciphering bioplastic production. Nat. Biotechnol. 2006, 24, 1227-1229. [CrossRef]

16. Lynd, L.R.; Larson, E.; Greene, N.; Laser, M.; Sheehan, J.; Dale, B.E.; McLaughlin, S.; Wang, M. The role of biomass in America's energy future: Framing the analysis. Biofuels Bioprod. Biorefining 2009, 3, 113-123. [CrossRef]

17. Calvo-Flores, F.G.; Dobado, J.A. Lignin as renewable raw material. ChemSusChem 2010, 3, 1227-1235. [CrossRef]

18. Kaparaju, P.; Serrano, M.; Thomsen, A.B.; Kongjan, P.; Angelidaki, I. Bioethanol, biohydrogen and biogas production from wheat straw in a biorefinery concept. Bioresour. Technol. 2009, 100, 2562-2568. [CrossRef]

19. Fernando, S.; Adhikari, S.; Chandrapal, C.; Murali, N. Biorefineries: Current status, challenges, and future direction. Energy Fuels 2006, 20, 1727-1737. [CrossRef]

20. FitzPatrick, M.; Champagne, P.; Cunningham, M.F.; Whitney, R.A. A biorefinery processing perspective. Treatment of lignocellulosic materials for the production of value-added products. Bioresour. Technol. 2010, 101, 8915-8922. [CrossRef]

21. Clark, J.H.; Budarin, V.; Deswarte, F.E.I.; Hardy, J.J.E.; Kerton, F.M.; Hunt, A.J.; Luque, R.; Macquarrie, D.J.; Milkowski, K.; Rodriguez, A.; et al. Green chemistry and the biorefinery: A partnership for a sustainable future. Green Chem. 2006, 8, 853-860. [CrossRef]

22. Dodds, D.R.; Gross, R.A. CHEMISTRY: Chemicals from biomass. Science 2007, 318, 1250-1251. [CrossRef]

23. Kumar, D.; Kumar, S. Mechanical Behaviour of Hybrid Bio-composite Reinforced with Walnut (Juglans regia L.) Shell Particle and Coconut Fibre. Int. J. Emerg. Technol. 2017, 8, 604-608.

24. Ohara, H. Biorefinery. Appl. Microbiol. Biotechnol. 2003, 62, 474-477. [CrossRef]

25. Rahul, K.; Gourav, G.; Ripudaman, S.N. Walnut Shell Reinforced Composite: A Review. Int. J. Sci. Eng. Res. 2016, 7, 179-189.

26. Fernandes, T.V.; Bos Klaasse, G.J.; Zeeman, G.; Sanders, J.P.M.; van Lier, J.B. Effects of thermo-chemical pre-treatment on anaerobic biodegradability and hydrolysis of lignocellulosic biomass. Bioresour. Technol. 2009, 100, 2575-2579. [CrossRef]

27. Sluiter, J.B.; Ruiz, O.R.; Scarlata, C.J.; Sluiter, A. Compositional Analysis of Lignocellulosic Feedstocks. Review and Description of Methods. J. Agric. Food Chem. 2010, 58, 9043-9053. [CrossRef]

28. Ioelovich, M. Correlation analysis of enzymatic digestibility of plant biomass. Biomass Convers. Biorefinery 2014, 4, 269-275. [CrossRef]

29. Biljuš, H.; Basarac Sertić, M. Potencijal i uloga biomase u hrvatskoj i europskoj energetskoj tranziciji. Drv. Ind. 2021, 72, 309-318. [CrossRef]

30. Misra, M.; Mohanty, A.K.; Pandey, J. Biocomposites: Design and Mechanical Performance; Woodhead Publishing, Elsevier: London, UK, 2015.

31. Antonović, A.; Jambreković, V.; Pervan, S.; Ištvanić, J.; Moro, M.; Zule, J. Utjecaj lokaliteta uzorkovanja na grupni kemijski sastav bijeli bukovine (Fagus sylvatica L.). Drv. Ind. 2007, 58, 119-125.

32. Antonović, A.; Jambreković, V.; Pervan, S.; Ištvanić, J.; Greger, K.; Bublić, A. A supplement to the research of native lignin of beech sapwood (Fagus sylvatica L.). Wood Res. 2008, 53, 55-68.

33. Antonović, A.; Ištvanić, J.; Medved, S.; Antolović, S.; Stanešić, J.; Kukuruzović, J.; Đurović, A.; Španić, N. Influence of Different Wood Species Chemical Composition on the Liquefaction Properties. In Implementation of Wood Science to Woodworking Sector; Sveučilište u Zagrebu Šumarski fakultet: Zagreb, Croatia, 2019; pp. 25-34.

34. Antonović, A.; Barčić, D.; Kljak, J.; Ištvanić, J.; Podvorec, T.; Stanešić, J. The quality of fired Aleppo pine wood (Pinus halepensis Mill) biomass for biorefinery products. Croat. J. For. Eng. J. Theory Appl. For. Eng. 2018, 39, 3013-3024.

35. Zając, G.; Szyszlak-Bargłowicz, J.; Gołębiowski, W.; Szczepanik, M. Chemical Characteristics of Biomass Ashes. Energies 2018, 11, 2885. [CrossRef]

36. Queirós, C.S.G.P.; Cardoso, S.; Lourenço, A. Characterization of walnut, almond, and pine nut shells regarding chemical composition and extract composition. Biomass Convers. Biorefinery 2020, 10, 175-188. [CrossRef]

37. Ashok, P. Bioethanol from Lignocellulosic Biomass Part I Pretreatment $65 \mathrm{f}$ the Substrates. In Handbook of Plant Based Biofuels; Taylor \& Francis: New York, NY, USA, 2009; pp. 121-139. 
38. Matin, A.; Krička, T.; Jurišić, V.; Bilandžija, N.; Voća, N.; Mrkšić, J. Energetska Iskoristivost Ljuske Oraha i Lješnjaka. Zbornik Radova 48. Hrvatskog i 8. Međunarodnog Simpozija Agronoma; Publisher: Poljoprivredni fakultet. Sveučilište Josipa Jurja Strossmayera u Osijeku. Dubrovnik, Croatia, 2013; pp. 836-840.

39. Demirbas, A. Fuel characteristics of olive husk and walnut, hazelnut, sunflower, and almond shells. Energy Source 2002, 24, 215-221. [CrossRef]

40. Pirayesh, H.; Khazaeian, A.; Tabarsa, T. The potential for using walnut (Juglans regia L.) shell as a raw material for wood-based particleboard manufacturing. Compos. Part B-Eng. 2012, 43, 3276-3280. [CrossRef]

41. Nabarlatz, D.; Farriol, X.; Montané, D. Autohydrolysis of almond shells for the production of xylo-oligosaccharides: Product characteristics and reaction kinetics. Ind. Eng. Chem. Res. 2005, 44, 7746-7755. [CrossRef]

42. Chen, H. Chemical Composition and Structure of Natural Lignocellulose. In Biotechnology of Lignocellulose: Theory and Practice; Chemical Industry Press: Beijing, China, 2014; pp. 25-69.

43. Chen, L.; Wang, X.; Yang, H.; Lu, Q.; Li, D.; Yang, Q.; Chen, H. Study on pyrolysis behaviors of non-woody lignins with TG-FTIR and Py-GC/MS. J. Anal. Appl. Pyrolysis 2015, 113, 499-507. [CrossRef]

44. Soleimani, M.; Kaghazchi, T. Adsorption of gold ions from industrial wastewater using activated carbon derived from hard shell of apricot stones-An agricultural waste. Bioresour Technol. 2008, 99, 5374-5383. [CrossRef]

45. Isfahlan, A.J.; Mahmoodzadeh, A.; Hasanzadeh, A.; Heidari, R.; Jamei, R. Antioxidant and antiradical activities of phenolic extracts from Iranian almond (Prunus amygdalus L.) hulls and shells. Turk. J. Biol. 2010, 34, 165-173. [CrossRef]

46. Martin, C.; Alriksson, B.; Sjöde, A.; Nilvebrant, N.O.; Jönsson, L.J. Dilute sulfuric acid pretreatment of agricultural and agroindustrial residues for ethanol production. Appl. Biochem. Biotechnol. 2007, 137, 339-352. [CrossRef]

47. Kacem, I.; Koubaa, M.; Maktouf, S.; Chaari, F.; Najar, T.; Chaabouni, M.; Ettis, N.; Ellouz Chaabouni, S. Multistage process for the production of bioethanol from almond shell. Bioresour. Technol. 2016, 211, 154-163. [CrossRef]

48. Ning, P.; Yang, G.; Hu, L.; Sun, J.; Shi, L.; Zhou, Y.; Wang, Z.; Yang, J. Recent advances in the valorization of plant biomass. Biotechnol. Biofuels 2021, 14, 102. [CrossRef]

49. González-García, P. Activated carbon from lignocellulosics precursors: A review of the synthesis methods, characterization techniques and applications. Renew Sustain. Energy Rev. 2018, 82, 1393-1414. [CrossRef] 